\title{
Low Cost Homemade System to Disinfect Food Items from SARS-CoV-2
}

\author{
Sushanta Debnath ${ }^{1}$
}

Received: 8 May 2020 / Accepted: 21 May 2020 / Published online: 30 May 2020

(C) Springer Science+Business Media, LLC, part of Springer Nature 2020

\section{To the Editor(s):}

In beginning era of the twenty-first century, many viral infections have attacked the human body. Severe Acute Respiratory Syndrome (SARS), Middle East Respiratory Syndrome (MERS) are few examples of these infections [1]. Now a days, COVID-19 pandemic has appeared in existence till December 2019. Though the mortality rate due to SARSCoV-2 is less, but the transmission capability is very high compared to the other viruses. Till the end of April, 2020, three millons people have been infected across the world due to this rapidly growing pandemic. Research works have been reported to reduce the transmission of infection in various dimensions $[2,3]$.

But there is no alternative rather than handling the essential food items which are purchased from the market. So, SARSCoV-2 virus can easily be transmitted from human to human through food commodities. Ultraviolet (UV) exposure based cheap method has been proposed for chemical free disinfection of the food items which can be easily designed at home with less technical knowledge.

UV-C light is required to be exposed into the food for disinfection purpose $[4,5]$. There are three types of UV rays namely UV-A, UV-B, UV-C [4]. Wavelength of UV-A ray in the electromagnetic spectrum lies between $315 \mathrm{~nm}$ to $400 \mathrm{~nm}$. Wavelength range of UV-B light is $280 \mathrm{~nm}$ to $315 \mathrm{~nm}$. Wavelength of UV-C light lies between $100 \mathrm{~nm}$ to $280 \mathrm{~nm}$.

A wooden box has been prepared to disinfect the food items from the virus. Since UV-C light is harmful to skin, it

This article is part of the Topical Collection on Education \& Training

Sushanta Debnath

sdebnathip1989@gmail.com

1 Department of Electrical Engineering, Gomati District Polytechnic, Udaipur, Tripura 799013, India is very much essential to disinfect the food items in a closed environment so that it does not come in contact with any human or animal. To meet this vital requirement, a closed wooden box is utilised to disinfect the food items which ensures the safety of human skin from UV-C light. Six number of lamps emitting UV-C light and a food holder are placed in the box for the operation. Arrangement of food holder and UV-C lamps inside the box is shown in fig. 1. Food is kept in the net type holder before supplying the power for $15 \mathrm{~min}$. The net type holder will produce shadow in the bottom side of the food. Multiple lamps in different positions are placed to ensure the presence of light in the complete surface of food during operation.

UV-C light is found to be effective to disinfect the food commodities without producing any chemical residue [5]. Advantage of the system is that it may be cheaply developed at home with less technical knowledge. In lockdown situation under rapidly growing COVID-19 pandemic, it becomes important to prepare such system at home to disinfect the food items before handling.

However, the taste of the food changes to a certain extend after processing [5]. Change of taste of food items is dependent upon the processing time and temperature parameters.

In summary, a cheap and simple method has been proposed for disinfecting the food items from SARS-CoV-2 virus during rapidly growing COVID-19 pandemic situation. Here, UV-C light is exposed to the food for disinfection purpose. No chemical residue is produced in the process. Also, this system may be developed at home with less technical knowledge. Limitation of the process is that the taste of food gets changed to some extend depending upon the processing time and temperature. Considering the present pandemic situation, this homemade system may become very helpful to break the chain of SARS-CoV-2 transmission occurring from the food items. 
Fig. 1 Disinfection box

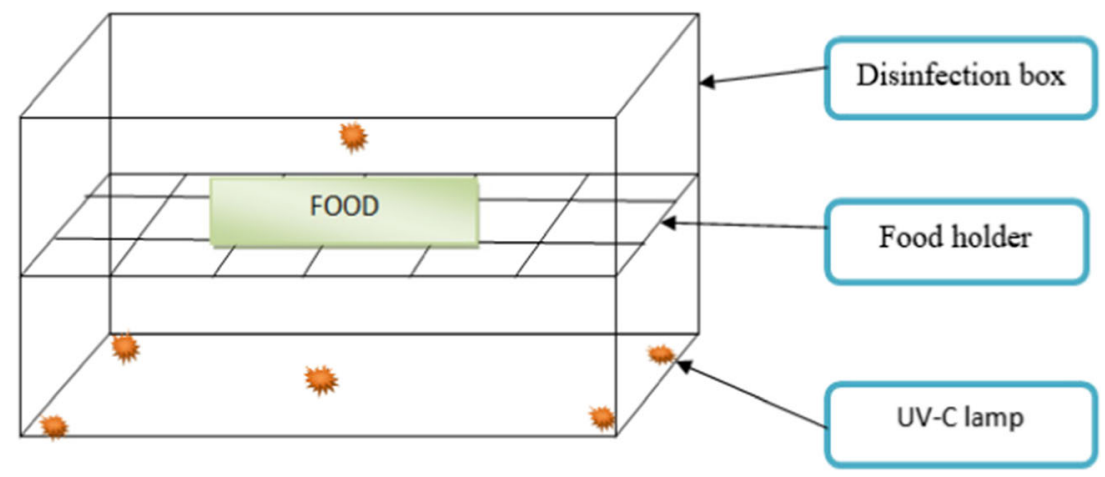

\section{Compliance with ethical standards}

This article does not contain any studies with human participants.

\section{Conflict of interest None.}

\section{References}

1. Da Costa, V.G., Moreli, M.L. \& Saivish, M.V. (2020), The emergence of SARS, MERS and novel SARS-2 coronaviruses in the 21st century. Arch Virol, https://doi.org/10.1007/s00705-020-04628-0

2. Khurana, S., Singh, P., Sinha, T. P., Bhoi, S., \& Mathur, P. (2020). Low-cost production of handrubs and face shields in developing countries fighting the COVID19 pandemic. American Journal of Infection Control, https://doi.org/10.1016/j.ajic.2020.03.016
3. Li, D. F., Cadnum, J. L., Redmond, S. N., Jones, L. D., \& Donskey, C. J. (2020). It's Not the Heat, It's the Humidity: Effectiveness of a Rice Cooker-Steamer for Decontamination of Cloth and Surgical Face Masks and N95 Respirators. American Journal of Infection Control, https://doi.org/10.1016/j.ajic.2020.04.012

4. Armellino, D., Walsh, T. J., Petraitis, V., \& Kowalski, W. (2019). Assessment of focused multivector ultraviolet disinfection withshadowless delivery using 5-point multisided sampling ofpatientcare equipment without manual-chemical disinfection. American journal of infection control, 47(4), 409-414.

5. Guerrero-Beltr n, J. A., \& Barbosa-C'novas, G. V. (2004). Advantages and limitations on processing foods by UV light. Food science and technology international, 10(3), 137-147.

Publisher's Note Springer Nature remains neutral with regard to jurisdictional claims in published maps and institutional affiliations. 